\title{
Detecting Long-Term Trends in Precipitable Water over the Tibetan Plateau by Synthesis of Station and MODIS Observations*
}

\author{
NING LU \\ State Key Laboratory of Resources and Environmental Information System, Institute of Geographic Sciences \\ and Natural Resources Research, Chinese Academy of Sciences, Beijing, and Jiangsu Center for Collaborative \\ Innovation in Geographical Information Resource Development and Application, Nanjing, China \\ KEVIN E. TRENBERTH \\ National Center for Atmospheric Research, Boulder, Colorado \\ JUN QIN AND KUN YANG \\ Key Laboratory of Tibetan Environment Changes and Land Surface Processes, Institute of Tibetan Plateau \\ Research, Chinese Academy of Sciences, and Chinese Academy of Sciences Center for Excellence in \\ Tibetan Plateau Earth System, Beijing, China \\ LING YAO \\ State Key Laboratory of Resources and Environmental Information System, Institute of Geographic Sciences \\ and Natural Resources Research, Chinese Academy of Sciences, Beijing, China \\ (Manuscript received 24 April 2014, in final form 13 November 2014)

\begin{abstract}
Long-term trends in precipitable water (PW) are an important component of climate change assessments for the Tibetan Plateau (TP). PW products from Moderate Resolution Imaging Spectroradiometer (MODIS) are able to provide good spatial coverage of PW over the TP but limited in time coverage, while the meteorological stations in the TP can estimate long-term PW but unevenly distributed. To detect the decadal trend in PW over the TP, Bayesian inference theory is used to construct long-term and spatially continuous PW data for the TP based on the station and MODIS observations. The prior information on the monthly-mean PW from MODIS and the 63 stations over the TP for 2000-06 is used to get the posterior probability knowledge that is utilized to build a Bayesian estimation model. This model is then operated to estimate continuous monthly-mean PW for 1970-2011 and its performance is evaluated using the monthly MODIS PW anomalies (2007-11) and annual GPS PW anomalies (1995-2011), with RMSEs below $0.65 \mathrm{~mm}$, to demonstrate that the model estimation can reproduce the PW variability over the TP in both space and time. Annual PW series show a significant increasing trend of $0.19 \mathrm{~mm} \mathrm{decade}^{-1}$ for the TP during the 42 years. The most significant PW increase of $0.47 \mathrm{~mm} \mathrm{decade}^{-1}$ occurs for 1986-99 and an insignificant decrease occurs for 2000-11. From the comparison of the PW data from JRA-55, ERA-40, ERA-Interim, MERRA, NCEP-2, and ISCCP, it is found that none of them are able to show the actual long-term trends and variability in PW for the TP as the Bayesian estimation.
\end{abstract}

\footnotetext{
* Supplemental information related to this paper is available at the Journals Online website: http://dx.doi.org/10.1175/JCLI-D-14-00303.s1.
}

Corresponding author address: Ning Lu, No.11A, Datun Road, Chaoyang, Beijing 100101, China.

E-mail: ning.robin@gmail.com

\section{Introduction}

Atmospheric water vapor is the most abundant greenhouse gas and plays a crucial radiative role in the global and regional climate system (Dessler et al. 2008; Solomon et al. 2010). Precipitable water (PW), as the measure of the depth of water in a column of the atmosphere if all the moisture were precipitated as rain, is important

DOI: 10.1175/JCLI-D-14-00303.1 
for climate analysis of energy budgets and hydrological cycles (Trenberth et al. 2009, 2011). The climatology (e.g., long-term monthly mean) of PW not only serves by itself as a sensitive indicator of deficiencies in the transport of water by moist convective schemes in models (Starr and Melfi 1990) but also could be used as a test of the models simulation of the quasi-equilibrium behavior of the atmosphere (Gao et al. 2006; Neelin et al. 2008). Furthermore, incorporation of this information into assimilation of regional climate model might also provide a basis for improved analysis of moisture fields and hydrologic processes (Kuo et al. 1993; Filiberti et al. 1994; Seko et al. 2011).

For the Tibetan Plateau (TP), the long-term PW can be used to describe and diagnose the climate change, by exploring the relation with solar radiation (Yang et al. 2012), surface heating (Yang et al. 2004), downstream floods and droughts (Xu et al. 2008), and rainfall patterns (Zhou and $\mathrm{Yu}$ 2005). Increasing PW trends of $3 \%-6 \%$ decade $^{-1}$ are found for the TP from 1970 to 1990 (Zhai and Eskridge 1997). Using the PW products from International Satellite Cloud Climatology Project (ISCCP), Zhang et al. (2013) investigate the relationship between $\mathrm{PW}$ and precipitation over the TP and find that PW in the 680-310-hPa layer of the atmosphere has increased significantly since the 1990s, with an upward trend of $6.45 \mathrm{~cm} \mathrm{decade}^{-1}$. Based on the satellite and reanalysis data, Lu et al. (2015) find that the PW trend for the integral over the TP from 2000 to 2010 is small and statistically insignificant. Meanwhile, significant increasing trends are found in the eastern and western TP with decreasing trends in the middle, which are affected by the regional warming and the large-scale atmospheric circulation. Therefore, trends and variations in PW are an integral part of the changes occurring in the TP's climate system. Detection of long-term trend in PW has been recognized as an important component of climate change assessments for the TP.

Datasets for analyzing long-term (a decade and more) changes in the PW over the TP consist of radiosonde, global positioning system (GPS), and satellite measurements; meteorological analyses based on station temperature-humidity observations; and reanalysis products based on assimilating observations using a general circulation model. Each of these contains varying degrees of insufficiencies that influence the interpretation and significance of PW trends. For instance, the insufficiency related to the ground measurements, such as radiosonde, GPS, and meteorological stations, is their spatial limitation; the insufficiency of satellite observations is limited to the temporal coverage; and the insufficiency of reanalysis data for the TP is the suitability for charactering long-term trends in PW because no other independent PW data are available for the TP.
Spatial representation of the station observations is a major concern of the long-term PW trend detection for the TP. There are approximately nine routine radiosonde stations over the vast TP (Zhai and Eskridge 1997). To extend the long-term PW data at more stations, previous studies have developed some empirical expressions to estimate PW using the station temperature-humidity observations, such as surface dewpoint (Reitan 1963; Smith 1966), air temperature, and relative humidity (Yang et al. 2006). Nevertheless, its spatial distribution is still limited over the TP. There are 63 meteorological stations with relatively long-term temperature-humidity records (starting in 1970) in the TP at present. The spatial distribution of these meteorological stations is especially uneven and heterogeneous (Fig. 1). Most stations are distributed in the eastern TP; only two stations are deployed in the western TP. Apparently, using the linear mean of these station observations simply to show the $\mathrm{PW}$ variations for the entire TP is impractical and prone to problems.

Satellite observations provide a feasible means to retrieve the PW distribution for the TP. Current water vapor products from satellites, such as Moderate Resolution Imaging Spectroradiometer (MODIS) near-infrared measurements, are able to represent the spatial and temporal variation of PW over the TP (Gao and Kaufman 2003; Gao et al. 2003). Lu et al. (2011) have used GPS PW measurements to evaluate the MODIS PW over the TP. The evaluation shows monthly PW variations over the TP can be observed accurately from MODIS. However, the temporal coverage of the MODIS data is limited (starting in 2000), not long enough to resolve the decadal trends and variability in the $\mathrm{PW}$ over the TP.

The suitability of reanalysis products, such as the 40-yr ECMWF Re-Analysis (ERA-40) or the ECMWF Interim Re-Analysis (ERA-Interim), for charactering longterm trends in climate variables has been still in debate (Thorne and Vose 2010; Dee et al. 2011). Simmons et al. (2010) show that surface temperature and humidity trends from ERA-40 and ERA-Interim are in excellent agreement with estimates obtained from climatological land station data, at the locations where such data are available. Additionally, the reanalyses provide observationally constrained values over other poorly observed land areas (Dee et al. 2011) (e.g., the TP). However, there remains the question whether these reanalysis products are able to detect the long-term trend in PW over the TP because there are no other independent long-term PW data available for now to validate the reanalyses for the TP.

To facilitate the detection of long-term trend in PW over the TP, we use Bayesian inference theory to construct a long-term (1970-2011) and spatially continuous PW dataset for the TP based on the station 


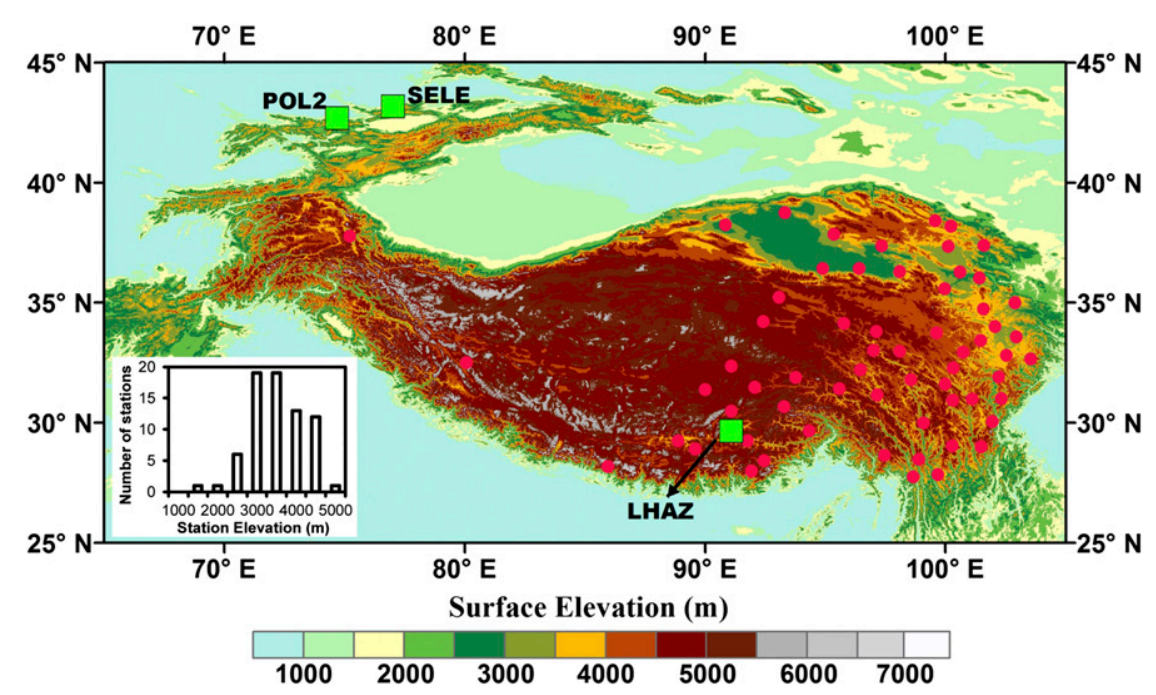

FIG. 1. Locations of the 63 meteorological stations used in the construction of long-term precipitable water vapor over the Tibetan Plateau. The station locations are marked with red solid dots. The green-filled rectangles denote the LHAZ, POL2, and SELE stations where GPS-measured PW data are used for the validation. Superimposed on the bottom left is the altitude distribution for these stations. The surface elevation is derived from the Shuttle Radar Topography Mission with a $1-\mathrm{km}$ resolution.

temperature-humidity and MODIS PW observations. PW estimated from station temperature-humidity observations reveal the long-term variations in the atmospheric water vapor. MODIS observations provide the distribution patterns of PW over the TP are treated as the prior knowledge. The two kinds of information are combined to build a Bayesian estimation model, estimating the long-term PW data for the TP. Therefore, this estimated long-term PW data can be regarded as the MODIS PW observations extended to pre-MODIS periods driven by the station observations. The long-term trends and variability in the PW for the TP are detected based on this estimated PW data, which are then compared with PW products from Japanese 55-year Reanalysis (JRA55), ERA-40, ERA-Interim, Modern-Era Retrospective Analysis for Research and Applications (MERRA), NCEP-DOE Reanalysis-2 (NCEP-2), and ISCCP.

The PW data, including the MODIS, GPS, and meteorological station observations are presented in section 2. The method description of the Bayesian estimation model is detailed in section 3. The estimated long-term PW results are validated and compared with reanalysis and satellite data in section 4, and a summary is presented in section 5 .

\section{Data}

There are three kinds of monthly-mean PW data used for modeling and validation in this study. The first one is the PW at each meteorological station estimated from the station long-term temperature-humidity observations. The second kind of PW data is from MODIS satellite observations for the study area $25^{\circ}-45^{\circ} \mathrm{N}, 65^{\circ}-105^{\circ} \mathrm{E}$. The third kind of PW data is from GPS measurements. The station PW estimations and part of MODIS PW are used to build the Bayesian estimation model and produce the long-term (1970-2011) and spatially continuous PW data for the TP. The other parts of MODIS PW and GPS-measured PW data are used for validation of the Bayesian estimation of PW.

\section{a. PW at meteorological stations}

The monthly-mean surface relative humidity and air temperature for 1970-2011 (42 yr) at the 63 meteorological stations over the TP are obtained from the China Meteorological Administration. The geographic locations of these stations are illustrated in Fig. 1 and listed in Table 1. All the stations provide full records without missing values. Monthly-mean PW at each station are empirically estimated (Yang et al. 2006) using

$$
\mathrm{PW}=0.042 \mathrm{rh} \cdot T_{\text {air }}^{-1} \exp \left(26.23-5416 T_{\text {air }}^{-1}\right),
$$

where $\mathrm{rh}$ is the surface relative humidity (\%) and $T_{\text {air }}$ is the 2-m air temperature (K). Equation (1) was locally parameterized, in which the coefficients have been calibrated by hundreds of PW samples from sounding profiles over the TP. Equation (1) has been tested to compare with the proposed parameterization with regard to surface dewpoint by Reitan (1963) and Smith (1966). They all show remarkably consistent PW estimation over the TP. 
TABLE 1. The geographic locations of the 63 meteorological stations in the Tibetan Plateau.

\begin{tabular}{|c|c|c|c|c|c|c|c|}
\hline WMO station code & Lat $\left({ }^{\circ} \mathrm{N}\right)$ & Lon $\left({ }^{\circ} \mathrm{E}\right)$ & Elevation (m) & WMO station code & Lat $\left({ }^{\circ} \mathrm{N}\right)$ & Lon $\left({ }^{\circ} \mathrm{E}\right)$ & Elevation (m) \\
\hline 51804 & 37.8 & 75.2 & 3090.1 & 56038 & 33.0 & 98.1 & 4200.0 \\
\hline 51886 & 38.3 & 90.9 & 2944.8 & 56046 & 33.8 & 99.7 & 3967.5 \\
\hline 52602 & 38.8 & 93.3 & 2770.0 & 56065 & 34.7 & 101.6 & 3500.0 \\
\hline 52645 & 38.4 & 99.6 & 3320.0 & 56067 & 33.4 & 101.5 & 3628.5 \\
\hline 52657 & 38.2 & 100.3 & 2787.4 & 56074 & 34.0 & 102.1 & 3471.4 \\
\hline 52713 & 37.9 & 95.4 & 3173.2 & 56079 & 33.6 & 103.0 & 3439.6 \\
\hline 52737 & 37.4 & 97.4 & 2981.5 & 56080 & 35.0 & 102.9 & 2910.0 \\
\hline 52754 & 37.3 & 100.1 & 3301.5 & 56106 & 31.9 & 93.8 & 4022.8 \\
\hline 52765 & 37.4 & 101.6 & 2850.0 & 56116 & 31.4 & 95.6 & 3873.1 \\
\hline 52818 & 36.4 & 94.9 & 2807.6 & 56125 & 32.2 & 96.5 & 3643.7 \\
\hline 52825 & 36.4 & 96.4 & 2790.4 & 56137 & 31.2 & 97.2 & 3306.0 \\
\hline 52836 & 36.3 & 98.1 & 3191.1 & 56144 & 31.8 & 98.6 & 3184.0 \\
\hline 52856 & 36.3 & 100.6 & 2835.0 & 56146 & 31.6 & 100.0 & 3393.5 \\
\hline 52868 & 36.0 & 101.4 & 2237.1 & 56151 & 32.9 & 100.8 & 3530.0 \\
\hline 52908 & 35.2 & 93.1 & 4612.2 & 56152 & 32.3 & 100.3 & 3893.9 \\
\hline 52943 & 35.6 & 100.0 & 3323.2 & 56167 & 31.0 & 101.1 & 2957.2 \\
\hline 55228 & 32.5 & 80.1 & 4278.6 & 56172 & 31.9 & 102.2 & 2664.4 \\
\hline 55279 & 31.4 & 90.0 & 4700.0 & 56173 & 32.8 & 102.6 & 3491.6 \\
\hline 55294 & 32.4 & 91.1 & 4800.0 & 56178 & 31.0 & 102.4 & 2369.2 \\
\hline 55299 & 31.5 & 92.1 & 4507.0 & 56182 & 32.7 & 103.6 & 2850.7 \\
\hline 55493 & 30.5 & 91.1 & 4200.0 & 56202 & 30.7 & 93.3 & 4488.8 \\
\hline 55578 & 29.3 & 88.9 & 3836.0 & 56247 & 30.0 & 99.1 & 2589.2 \\
\hline 55591 & 29.7 & 91.1 & 3648.9 & 56251 & 30.9 & 100.3 & 3000.0 \\
\hline 55598 & 29.3 & 91.8 & 3551.7 & 56312 & 29.7 & 94.3 & 2991.8 \\
\hline 55655 & 28.2 & 86.0 & 3810.0 & 56357 & 29.1 & 100.3 & 3727.7 \\
\hline 55680 & 28.9 & 89.6 & 4040.0 & 56374 & 30.1 & 102.0 & 2615.7 \\
\hline 55690 & 28.0 & 92.0 & 4280.3 & 56434 & 28.7 & 97.5 & 2327.6 \\
\hline 55696 & 28.4 & 92.5 & 3860.0 & 56444 & 28.5 & 98.9 & 3319.0 \\
\hline 56004 & 34.2 & 92.4 & 4533.1 & 56462 & 29.0 & 101.5 & 2987.3 \\
\hline 56021 & 34.1 & 95.8 & 4175.0 & 56533 & 27.8 & 98.7 & 1583.3 \\
\hline 56029 & 33.0 & 97.0 & 3681.2 & 56543 & 27.8 & 99.7 & 3276.7 \\
\hline 56034 & 33.8 & 97.1 & 4415.4 & & & & \\
\hline
\end{tabular}

Note that, although this estimation is not the actual PW observation, it acts as good surrogate and reflects the varied status of the atmospheric water vapor. In section 3, the estimated PW from station temperaturehumidity observations will be combined with the MODIS PW observations through the Bayesian inference theory.

\section{b. PW from satellite observations}

For the satellite water vapor products, the monthlymean PW data for 2000-11 (12 yr) are derived from MODIS collection- 5 products (MOD05) for the area $25^{\circ}-45^{\circ} \mathrm{N}, 65^{\circ}-105^{\circ} \mathrm{E}$ (the Himalayas and Tibetan Plateau). The spatial resolution for the MODIS PW data is $1^{\circ} \times 1^{\circ}$. Since the method of PW information fusion depends on the spatial distribution of MODIS PW, the constructed long-term PW datasets for the TP have the same spatial resolution as the MODIS PW data. The first $7 \mathrm{yr}$ of MODIS PW (2000-06), along with the station-estimated PW over the same period, are employed to build the Bayesian estimation model. The remaining $5 \mathrm{yr}$ of MODIS PW (2007-11) are used to validate the Bayesian estimated PW grid by grid.

\section{c. PW from GPS measurements}

The GPS data are obtained from NCAR global, 2-hourly GPS PW dataset (Wang et al. 2007), which was derived from ground-based GPS measurements of zenith path delay using three different resources: the International Global Navigation Satellite Systems Service tropospheric products, U.S. SuomiNet products, and Japanese GPS Earth Observation Network data. There are three stations of GPS data [Almaty, Kazakhstan (SELE), Bishkek, Kyrgyzstan (POL2), and Lhasa, China (LHAZ)] within the study area, of which only one GPS station (LHAZ) is on the TP. The locations of these GPS stations are shown in Fig. 1 (green-filled rectangles) and listed in Table 2 with date range for the records. Data records start in 1995 for the POL2 station and 1997 for the other two stations. To validate the monthly-mean PW from Bayesian estimation, the 2-hourly GPS PW are averaged for 
TABLE 2. Information on GPS stations for the validation.

\begin{tabular}{ccccc}
\hline \hline Station code & Lat $\left({ }^{\circ} \mathrm{N}\right)$ & Lon $\left({ }^{\circ} \mathrm{E}\right)$ & Elevation $(\mathrm{m})$ & Time range \\
\hline SELE & 43.18 & 77.02 & 1384.10 & $1997-2011$ \\
POL2 & 42.68 & 74.69 & 1754.00 & $1995-2011$ \\
LHAZ & 29.66 & 91.10 & 3656.60 & $1997-2011$ \\
\hline
\end{tabular}

each month on the daily basis at each individual station. Records with over $5 \%$ missing data during a day or a month are not used.

\section{Bayesian estimation model}

As mentioned above, the spatial distribution of PW over the TP can be obtained using the MODIS data. From the perspective of Bayesian inference theory, these distribution patterns of $\mathrm{PW}$ are regarded as providing prior knowledge that can be learned for giving the posterior distribution over the weights for station observations. We use Bayesian linear regression to build a Bayesian estimation model for determining the weight vector for each station. This model can estimate long-term and spatially continuous PW over the TP by importing the station PW estimations.

The common form of linear model is

$$
\mathbf{y}=\mathbf{X} \boldsymbol{\beta}+\varepsilon,
$$

where $\mathbf{y}$ is an $N \times 1$ vector of MODIS PW observations (defined as $\mathbf{P} \mathbf{W}^{\mathrm{mod}}$ ) for one grid point, $\mathbf{X}$ is an $N \times M$ matrix of PW estimated from station temperaturehumidity observations (defined as $\mathbf{P} \mathbf{W}^{\text {sta }}$ ), $N$ is the number of MODIS PW observations at this grid point (since $7 \mathrm{yr}$ of monthly-mean MODIS PW are used in the modeling, so $N$ is $7 \times 12=84), M$ is the number of meteorological stations ( $M=63$ in this case), $\boldsymbol{\beta}$ is a $1 \times M$ vector of regression coefficient (i.e., weight vector for stations), and $\varepsilon$ is an $N \times 1$ vector of independent and identical normally distributed random errors [i.e., $\boldsymbol{\varepsilon} \sim \operatorname{Normal}\left(0, \sigma^{2}\right)$ ].

The ordinary least squares (OLS) regression is commonly used to estimate $\boldsymbol{\beta}$ by minimizing the cost function of the sum of the squares of residuals,

$$
\hat{\boldsymbol{\beta}}=\left(\mathbf{X}^{\mathrm{T}} \mathbf{X}\right)^{-1} \mathbf{X}^{\mathrm{T}} \mathbf{y}
$$

The major issue in OLS regression is that it tends to describe random noise instead of the underlying relationship when the predictor variables are highly correlated, leading to the overfitting issue (see Fig. 3). It is especially true for this application because the PW estimations of many stations in the eastern TP are highly correlated.

To address this issue, Bayesian linear regression introduces a prior probability distribution over the model parameter $\boldsymbol{\beta}$. To obtain the Bayesian solution, the conditional likelihood is need to be specified and appropriate conjugate prior as well. Given that a zero-mean isotropic Gaussian prior such that $p(\boldsymbol{\beta} \mid \alpha)=G(\boldsymbol{\beta} ; 0, \alpha \mathbf{l})$ (Gregory 2005) is conjugate to the likelihood function, the posterior distribution of $\boldsymbol{\beta}$ is also Gaussian, expressed as follows (Bishop 2006):

$$
\begin{aligned}
& p\left(\boldsymbol{\beta} \mid \mathbf{P} \mathbf{W}^{\mathrm{mod}}, \alpha, \sigma^{2}\right) \\
& =\frac{p\left(\mathbf{P} \mathbf{W}^{\text {mod }} \mid \boldsymbol{\beta}, \sigma^{2}\right) p(\boldsymbol{\beta} \mid \alpha)}{p\left(\mathbf{P W}^{\text {mod }} \mid \alpha, \sigma^{2}\right)} \propto G(\boldsymbol{\beta} ; \mathbf{m}, \mathbf{S}),
\end{aligned}
$$

with

$$
\begin{aligned}
& \mathbf{m}=\sigma^{-2} \mathbf{S}\left(\mathbf{P} \mathbf{W}^{\text {sta }}\right)^{\mathrm{T}} \mathbf{P} \mathbf{W}^{\text {mod }} \text { and } \\
& \mathbf{S}=\left[\alpha \mathbf{I}+\sigma^{-2}\left(\mathbf{P} \mathbf{W}^{\text {sta }}\right)^{\mathrm{T}} \mathbf{P} \mathbf{W}^{\text {sta }}\right]^{-1},
\end{aligned}
$$

where $p(\cdot)$ is the probability density function, $G(\cdot)$ is the Gaussian distribution, $\mathbf{m}$ is the posterior mean of weight vector, $\mathbf{S}$ is the covariance matrix of weight vector, $I$ is the identity matrix, $\sigma^{2}$ is the Gaussian noise variance, and $\alpha$ is the variance of weight vector (which can be regarded as the regulation term for the weight vector; Qin et al. 2013). In Eq. (4), $\mathbf{m}$ is regarded as the Bayesian estimation for the weight vector $\boldsymbol{\beta}$. Therefore, Eq. (2) becomes

$$
\mathbf{y}=\mathbf{X m}+\boldsymbol{\varepsilon} .
$$

To solve for $\mathbf{m}$, the parameters $\alpha$ and $\sigma^{2}$ have to be solved at first. In this paper, these parameter values are fitted using maximum likelihood estimation.

According to Eq. (4), the marginal likelihood function (aka model evidence) is

$$
\begin{aligned}
p\left(\mathbf{P} \mathbf{W}^{\mathrm{mod}} \mid \alpha, \sigma^{2}\right) & =\int p\left(\mathbf{P} \mathbf{W}^{\mathrm{mod}} \mid \boldsymbol{\beta}, \sigma^{2}\right) p(\boldsymbol{\beta} \mid \alpha) d \beta \\
& =(2 \pi)^{-M / 2}|\mathbf{C}|^{-1 / 2} \exp \left[-\frac{1}{2}\left(\mathbf{P} \mathbf{W}^{\mathrm{mod}}\right)^{\mathrm{T}} \mathbf{C}^{-1} \mathbf{P} \mathbf{W}^{\mathrm{mod}}\right],
\end{aligned}
$$


with

$$
\mathbf{C}=\sigma^{2} \mathbf{I}+\alpha^{-1}\left(\mathbf{P} \mathbf{W}^{\text {sta }}\right)^{\mathrm{T}} \mathbf{P} \mathbf{W}^{\text {sta }} .
$$

Using Eq. (8), we can then write the log of the marginal likelihood in the form

$$
\begin{aligned}
& \ln p\left(\mathbf{P} \mathbf{W}^{\bmod } \mid \alpha, \sigma^{2}\right)=\frac{M}{2} \ln \alpha+\frac{N}{2} \ln \sigma^{2}-\frac{1}{2} \ln \left|\mathbf{S}^{-1}\right| \\
& -\frac{\sum_{n=1}^{N}\left(\mathbf{P} \mathbf{W}_{n}^{\mathrm{mod}}-\mathbf{m}^{\mathrm{T}} \mathbf{P} \mathbf{W}_{n}^{\mathrm{sta}}\right)}{2 \sigma^{2}} \\
& -\frac{\alpha \mathbf{m}^{\mathrm{T}} \mathbf{m}}{2}-\frac{N}{2} \ln (2 \pi) \text {. }
\end{aligned}
$$

Consider the derivative with respect to $\alpha$, and we have

$$
\frac{d \ln p\left(\mathbf{P W}{ }^{\mathrm{mod}} \mid \alpha, \sigma^{2}\right)}{d \alpha}=\frac{M}{2 \alpha}-\frac{1}{2} \operatorname{tr}(\mathbf{S})-\frac{\mathbf{m}^{\mathrm{T}} \mathbf{m}}{2} .
$$

By setting the above derivative to zero, $\alpha$ can be obtained by

$$
\alpha=\frac{M}{\mathbf{m}^{\mathrm{T}} \mathbf{m}+\operatorname{tr}(\mathbf{S})} .
$$

Similarly, setting $d \ln p\left(\mathbf{P W} \mathbf{m o d}^{\bmod } \alpha, \sigma^{2}\right) / d \sigma^{2}=0$ gives

$$
\sigma^{2}=\frac{N}{\sum_{n=1}^{N}\left(\mathbf{P} \mathbf{W}_{n}^{\text {mod }}-\mathbf{m}^{\mathrm{T}} \mathbf{P} \mathbf{W}_{n}^{\text {sta }}\right)+\operatorname{tr}\left[\left(\mathbf{P} \mathbf{W}^{\text {sta }}\right)^{\mathrm{T}} \mathbf{P} \mathbf{W}^{\text {sta }} \mathbf{S}\right]},
$$

where $\operatorname{tr}(\cdot)$ is the trace of the matrix. Since the weight vector $\boldsymbol{\beta}$ is marginalized out in Eq. (8), we can regard it as a latent variable and then maximize this marginal likelihood function with respect to parameters $\alpha$ and $\sigma^{2}$ using the expectation maximization (EM) algorithm.

The EM algorithm is an iterative method that alternates between an expectation step and a maximization step. First, random values for $\sigma^{2}$ and $\alpha$ are generated from the gamma distribution to compute the expectation of the log-likelihood during the expectation step. Second, the expected parameters $\mathbf{m}$ and $\mathbf{S}$ (obtained in the expectation step) are introduced to the maximization step for estimating the new values for $\sigma^{2}$ and $\alpha$ that maximize the expected log-likelihood. Third, these new parameter estimates are then used to compute the posterior values for $\mathbf{m}$ and $\mathbf{S}$ in the next expectation step. Fourth, the values for $\sigma^{2}$ and $\alpha$ are recomputed in the next maximization step. Finally, the procedure iterates the expectation and maximization steps until convergence. The convergence rate of this method is fast; approximately eight loops are enough.
Because the log-likelihood function may have multiple local maxima (Chen and Martin 2009), the iterative procedure in the EM algorithm, in some cases, does not guarantee the global maximum. To determine the best fitted weight vector $\mathbf{m}$, therefore, we define a number of random starting values (up to 1000) for the parameters $\sigma^{2}$ and $\alpha$ in the first expectation step, and thus $\mathbf{m}$ is finally derived from the model with the largest log-likelihood value.

\section{Results and discussion}

In this study, PW data from the stations and MODIS for 2000-06 are used to build the Bayesian estimation model first. This training process produces nearly identical PW results to the MODIS PW, with all the points almost exactly on the identity line (not shown). Whereafter, this built Bayesian estimation model, driven by the station PW estimations from 1970 to 2011, reproduces long-term and spatially continuous monthlymean $\mathrm{PW}$ for the TP ( $\left.\mathrm{PW}_{\text {bayes }}\right)$.

\section{a. Evaluation of the Bayesian estimation of PW}

Monthly-mean MODIS PW ( $\mathrm{PW}_{\text {mod }}$ ) for 2007-11 and GPS PW ( $\left.\mathrm{PW}_{\mathrm{gps}}\right)$ measured at three stations for 1.5 decades over the TP are used to evaluate the $\mathrm{PW}_{\text {bayes }}$ data. The performance of the $\mathrm{PW}_{\text {bayes }}$ is evaluated using three metrics: mean bias (between $\mathrm{PW}_{\text {bayes }}$ and $\mathrm{PW}_{\text {mod }}$ or $\mathrm{PW}_{\mathrm{gps}}$; in millimeters), root-mean-square error (RMSE; in millimeters), and correlation coefficient $R$.

The monthly-mean $\mathrm{PW}_{\text {bayes }}$ for 2007-11 are compared with the monthly-mean $\mathrm{PW}_{\text {mod }}$ for each year. (The comparisons and statistical measures are shown in Figs. S1a-e of the supplemental material.) To illustrate the Bayesian model's capability in reproducing temporal variability in PW by removing the annual cycle, we use monthly PW anomaly relative to the reference period of 2007-11 instead of monthly-mean PW for the comparison of PW variability, as shown in Figs. 2a-e. The ensemble of monthly $\mathrm{PW}_{\text {bayes }}$ anomalies at each grid over the TP show high correlation to the monthly $\mathrm{PW}_{\text {mod }}$ anomalies, with a correlation coefficient $R$ above 0.80 and an RMSE below $0.65 \mathrm{~mm}$ for each year, suggesting that Bayesian estimation model is able to accurately produce $\mathrm{PW}$ values for other years that are not involved into the model training. The comparison of the monthly anomalies between $\mathrm{PW}_{\text {bayes }}$ and $\mathrm{PW}_{\text {mod }}$ for the integral over the TP is also illustrated in Fig. $2 \mathrm{f}$. The agreement of the two PW data is very good, with an $R$ of 0.89 and an RMSE of $0.24 \mathrm{~mm}$. All the points are quite close to the identity line, indicating that the monthly $\mathrm{PW}_{\text {bayes }}$ anomalies agree well with the monthly $\mathrm{PW}_{\text {mod }}$ anomalies. 

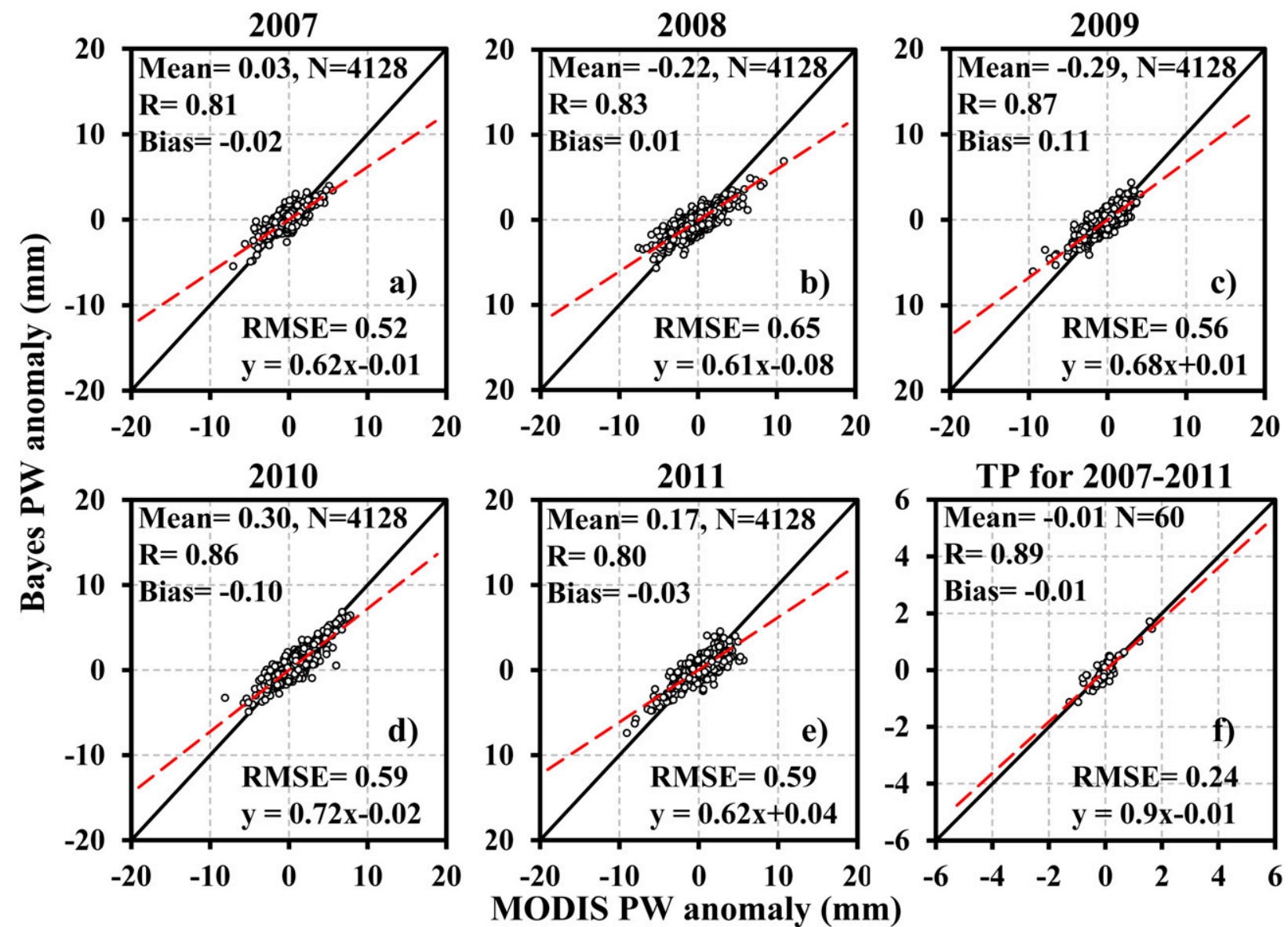

FIG. 2. Comparisons of the monthly anomalies of precipitable water estimated from the Bayesian estimation model with that observed from MODIS (a)-(e) for 2007-11 at each grid over the Tibetan Plateau and (f) for the integral over Tibetan Plateau. Note that $N$ here shows the number of the data pairs in the plot. Mean indicates the mean value of the precipitable water anomalies of MODIS in the plot. The unit for mean, bias, and RMSE given in each panel is millimeters.

The monthly-mean PW for 2007-11 are estimated by the OLS regression as well $\left(\mathrm{PW}_{\text {ols }}\right.$; see Fig. $\mathrm{S} 2$ of the supplemental material). The annual cycles in monthlymean $\mathrm{PW}_{\mathrm{ols}}$ are removed in the same manner as the $\mathrm{PW}_{\text {bayes }}$ to obtain the monthly $\mathrm{PW}_{\mathrm{ols}}$ anomalies that are compared with the monthly-mean $\mathrm{PW}_{\text {mod }}$ at each grid over the TP for each year, as shown in Figs. 3a-e. As compared with the Bayesian estimation model, data pairs of the monthly $\mathrm{PW}_{\mathrm{ols}}$ anomalies are scattered by a much wider range, implying the overfitting issue of the OLS regression leads to poor estimations. The comparison for the TP in Fig. 3f indicates that the monthly-mean PW estimated by the OLS regression cannot account for the monthly PW variability over the TP.

Because the $\mathrm{PW}_{\mathrm{gps}}$ data length is relatively long (up to $15 \mathrm{yr}$ ) and the linear trend is detected from the annual PW data, the comparison of $\mathrm{PW}_{\text {bayes }}$ with $\mathrm{PW}_{\mathrm{gps}}$ is performed on annual scale. Figure 4 shows the comparison between the annual anomalies of $\mathrm{PW}_{\text {bayes }}$ and $\mathrm{PW}_{\mathrm{gps}}$ for about
$15 \mathrm{yr}$ at the stations of LHAZ, POL2, and SELE. For the LHAZ station on the TP, annual $\mathrm{PW}_{\text {bayes }}$ anomalies match well with annual $\mathrm{PW}_{\mathrm{gps}}$ anomalies, with a high correlation coefficient of 0.85 and an RMSE of $0.32 \mathrm{~mm}$. For the POL2 and SELE stations outside the TP, RMSEs of annual anomalies between $\mathrm{PW}_{\text {bayes }}$ and $\mathrm{PW}_{\mathrm{gps}}$ are relatively larger than the LHAZ station but still well correlated. $\mathrm{PW}_{\text {bayes }}$ have better performance for the SELE station as compared with the POL2 station. This comparison demonstrates that the agreement of annual anomalies between $\mathrm{PW}_{\text {bayes }}$ and $\mathrm{PW}_{\mathrm{gps}}$ is quite good for the TP.

\section{b. Comparison with $P W$ of spatial interpolation}

Figure 5 shows an example of the spatial distribution of PW over the TP in spring, summer, autumn, and winter of 2009, respectively. The MODIS PW observation (Fig. 5a) clearly shows that PW values over the TP are much smaller than those over the surrounding low-elevation 

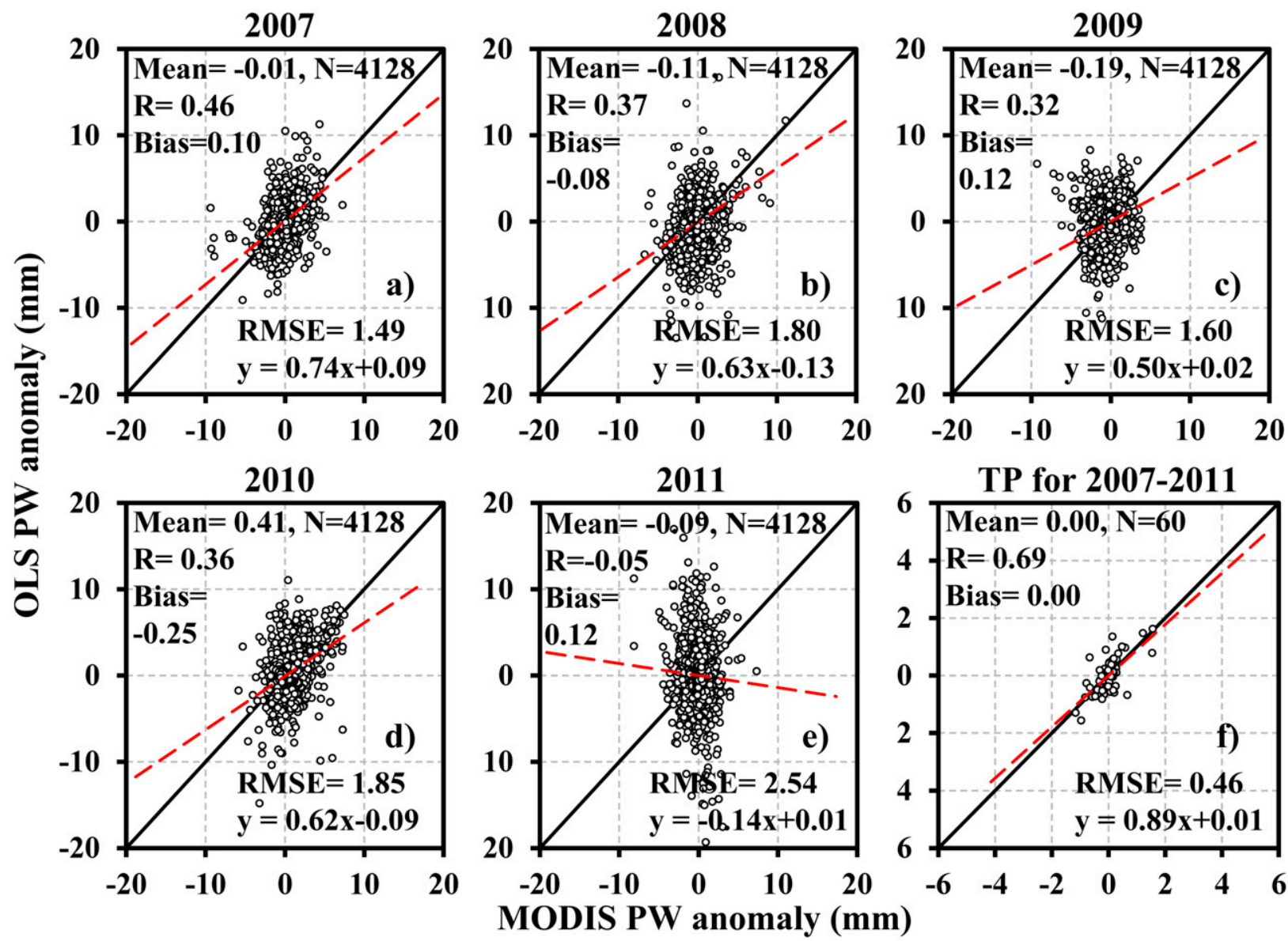

FIG. 3. As in Fig. 2, but for the ordinary least squares regression.

regions. Particularly in summer, when the summer monsoon brings abundant moisture evaporated from the Arabian Sea and the Bay of Bengal to the TP south slope, there is a sharp water vapor gradient between the
Indian subcontinent and the TP, caused by the moisture blocking of the Himalayas (Gao et al. 2003; Lu et al. 2015). The continuous PW distribution is also interpolated from the discrete 63 station points by two commonly used
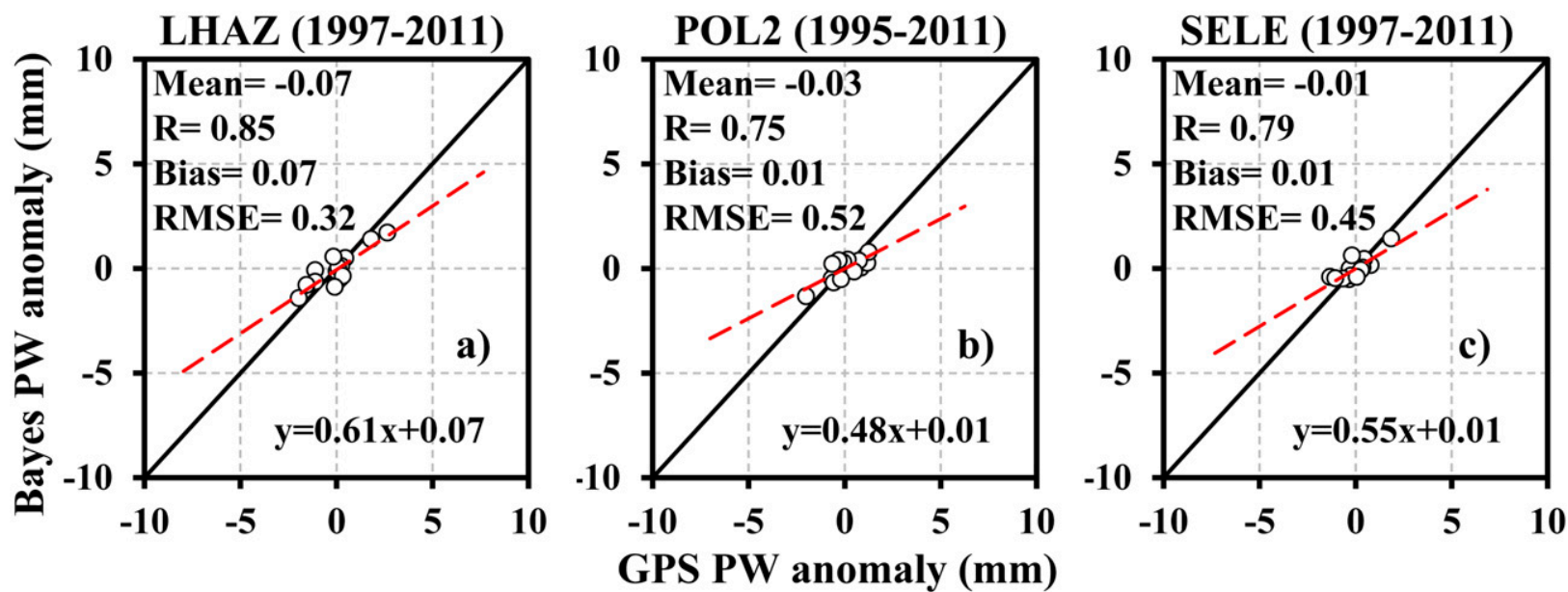

FIG. 4. Comparisons of the annual anomalies of precipitable water estimated from the Bayesian estimation model with that measured at three GPS stations. 


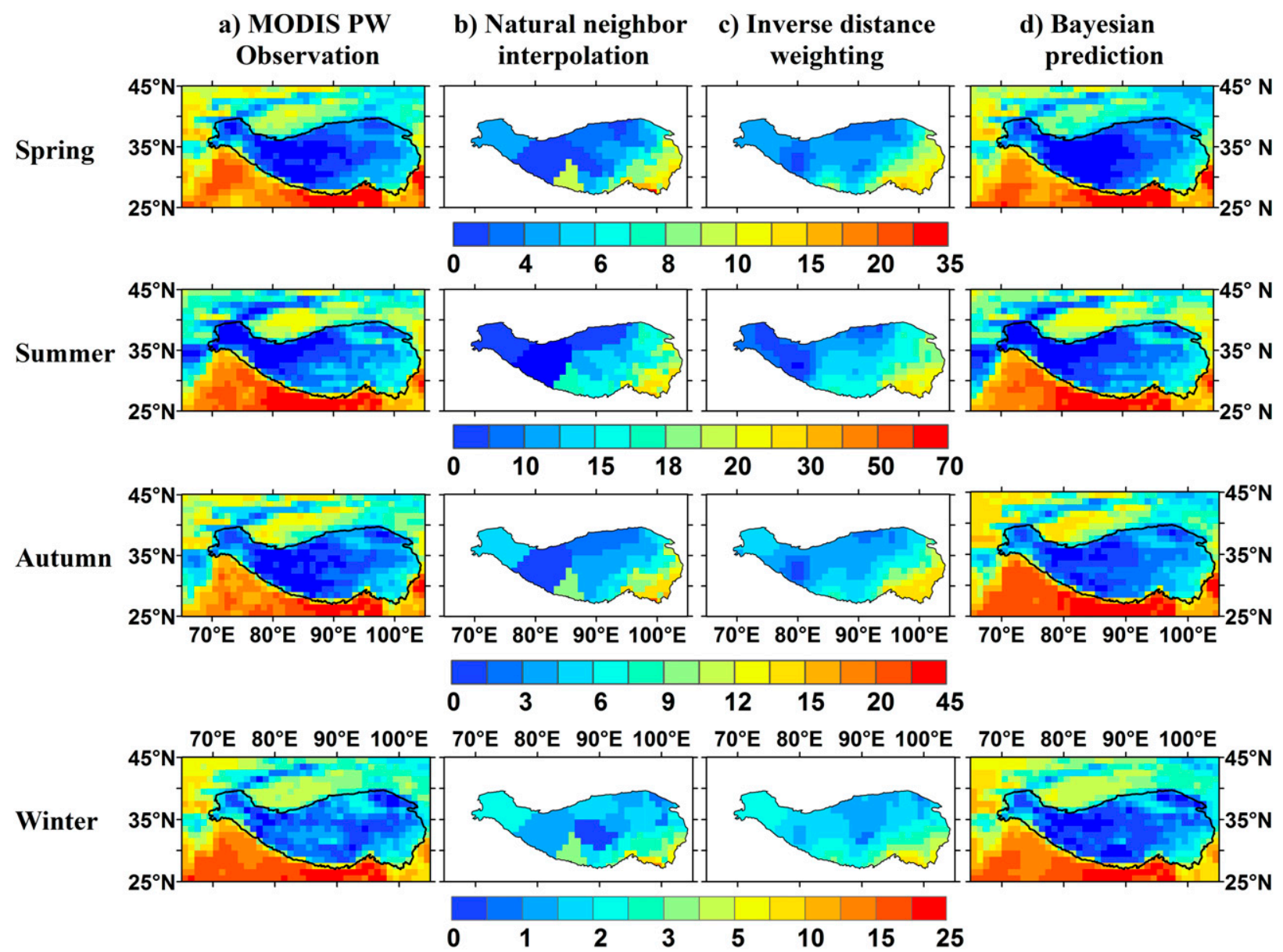

FIG. 5. Precipitable water over the Tibetan Plateau (top)-(bottom) in spring, summer, autumn, and winter of 2009 (a) observed from MODIS, interpolated from the station observations with (b) natural neighbor interpolation and (c) inverse distance weighting, and (d) estimated by the Bayesian estimation model. The polygon shape encompasses the Tibetan Plateau. The scales of color bar are different for each season to clearly illustrate the spatial pattern of precipitable water over the Tibetan Plateau.

interpolation methods: that is, natural neighbor interpolation (Fig. 5b) and inverse distance weighting (Fig. 5c), respectively. For the natural neighbor interpolation, a Voronoi diagram (i.e., Thiessen polygons) is constructed for all the station points and a new Voronoi polygon is created around the interpolation point. The proportion of overlap between this new polygon and the initial polygons are then used as the weights for interpolation. For the inverse distance weighting interpolation, a linearly weighted combination of a set of sample points is used to determine the value for the interpolation point. The sample radius to perform interpolation is defined as variable function with 12 nearest sample points.

Figure $5 \mathrm{~d}$ shows the spatial distribution of $\mathrm{PW}$ estimated by the Bayesian estimation model for the four seasons. As visually compared with the above interpolation methods (Figs. 5b,c), the Bayesian estimation model reproduces very similar PW spatial pattern over the TP to the
MODIS PW. Even for the high PW over the TP south slope, where there are no stations, the Bayesian estimation model still works well. This is because water vapor over this domain are spatially correlated; high water vapor over the Indian subcontinent contributes to the increased PW over the inner TP through water vapor transport, which means the success of the Bayesian estimation model essentially depends on the physical intercorrelation of the atmospheric water vapor.

\section{c. Trend of PW during 1970-2011 over the Tibetan Plateau}

Using the Bayesian estimation model, we construct the monthly-mean $\mathrm{PW}_{\text {bayes }}$ for the TP for 1970-2011 (42 yr) estimated by inputting the long-term station PW estimations. Based on this continuous $\mathrm{PW}_{\text {bayes }}$ data, annual PW anomalies for the integral over the TP, obtained as deviations from the 1970-2011 period, are calculated (Fig. 6a, blue dashed line). To improve the visualization 
a)

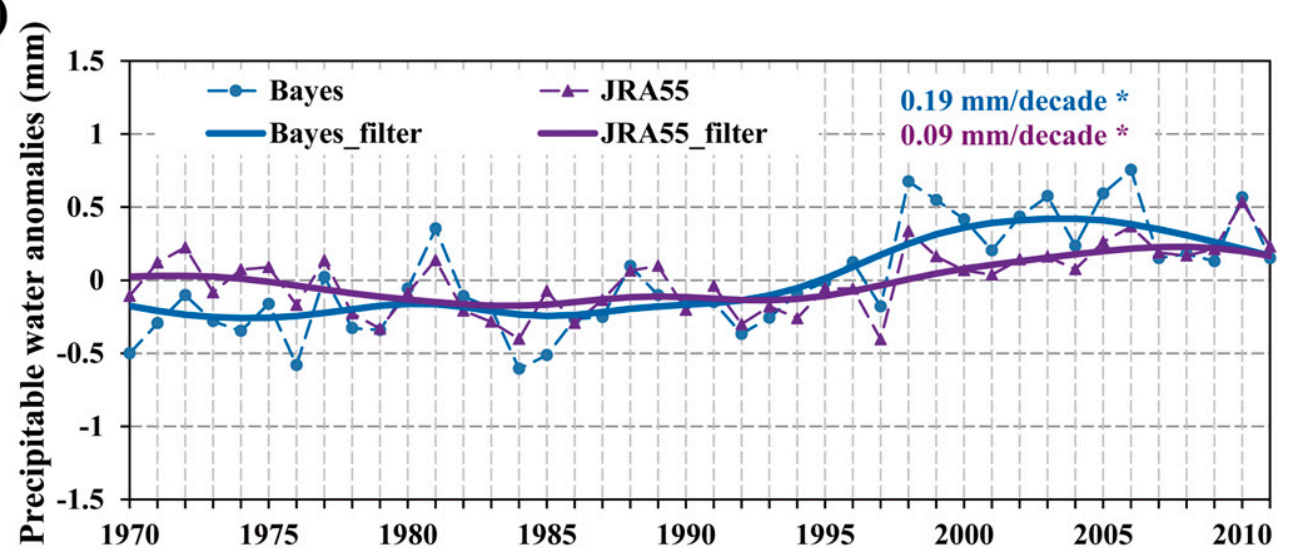

b)

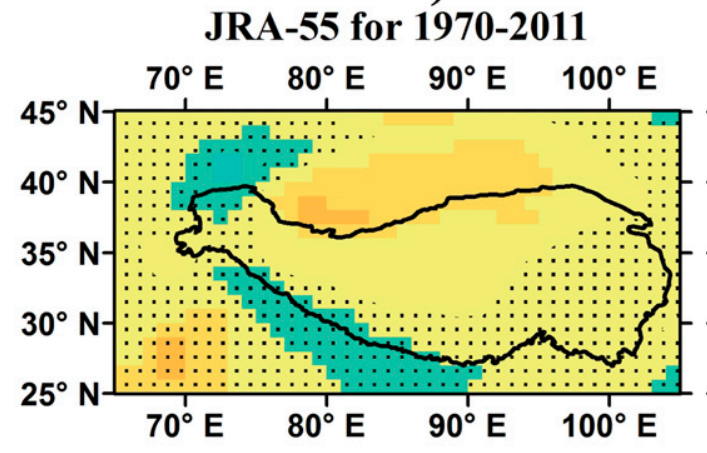

c)

Bayesian estimation for 1970-2011
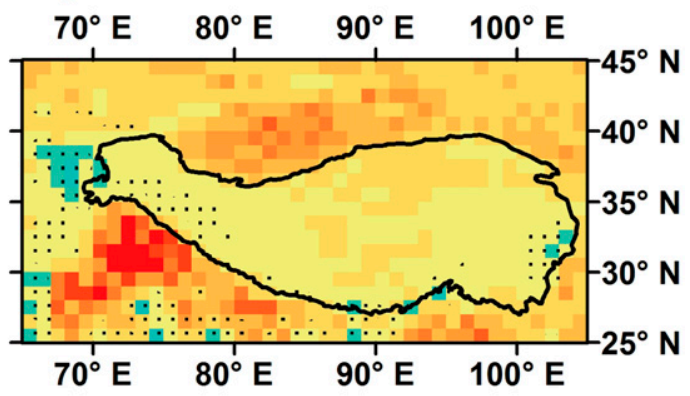

Linear trends 1979-2011 in mm per decade

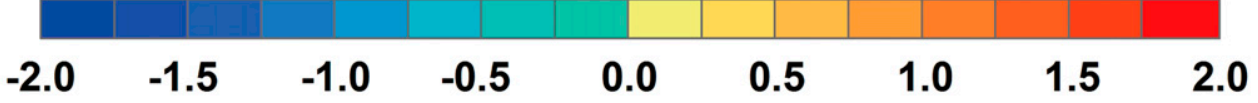

FIG. 6. The precipitable water for the Tibetan Plateau for 1970-2011 with (a) annual anomaly series (thin dashed line), plotted together with a 15-yr Gaussian low-pass filter (thick line), and the linear trends derived from (b) JRA-55 and (c) Bayesian estimation. The series are expressed as anomalies relative to the 1970-2011 reference period. In all panels, stippling indicates where the linear trends are insignificant at the $95 \%$ confidence level over the entire period.

of the decadal variability, the PW series are plotted together with their 15-yr Gaussian low-pass filer. On the annual basis, the mean PW series over the TP vary gently for 1970-85. Subsequently, a strong increasing tendency of PW is shown before the 2000s, followed by a decrease during the $2000-11$ period. We calculate the linear trends of the PW series for different subperiods by means of least squares fitting. Statistically significant linear trend is determined when $p$ value $<0.05$, which is estimated using a two-tailed Student's $t$ test. Because the evaluation of $\mathrm{PW}_{\text {bayes }}$ anomalies in section $4 \mathrm{a}$ evidences that the $\mathrm{PW}_{\text {bayes }}$ anomalies can reflect the long-term PW variability on the TP, the linear trend derived from these anomalies is reliable. The PW series for the TP exhibits a significant increasing trend for 1970-2011 with a rate of $0.19 \mathrm{~mm}$ decade $^{-1}$. For the subperiods, it shows a significant increase of $0.47 \mathrm{mmdecade}^{-1}$ for $1986-99$ and an insignificant decrease of $-0.09 \mathrm{~mm} \mathrm{decade}^{-1}$ for $2000-11$. Figure $6 c$ shows the linear trends of PW for 1970-2011 for each grid over the TP. Stippling indicates where the linear trends are insignificant at the $95 \%$ confidence level over the entire period. It can be seen that almost all the TP regions experience significant increase in PW during the last 42 years.

\section{d. Comparison with PW trends of reanalysis and satellite data}

The comparison of PW linear trends between the Bayesian estimation and the JRA-55 for 1970-2011 is shown in Fig. 6. The increasing trend of TP PW for 1970-2011 is $0.09 \mathrm{~mm} \mathrm{decade}^{-1}$ (significant) for the JRA-55 (Fig. 6a), which means the value of linear trend from JRA-55 is just half of the Bayesian estimation $\left(0.19 \mathrm{~mm} \mathrm{decade}^{-1}\right)$. By comparison with the linear trends pattern from the 
a)

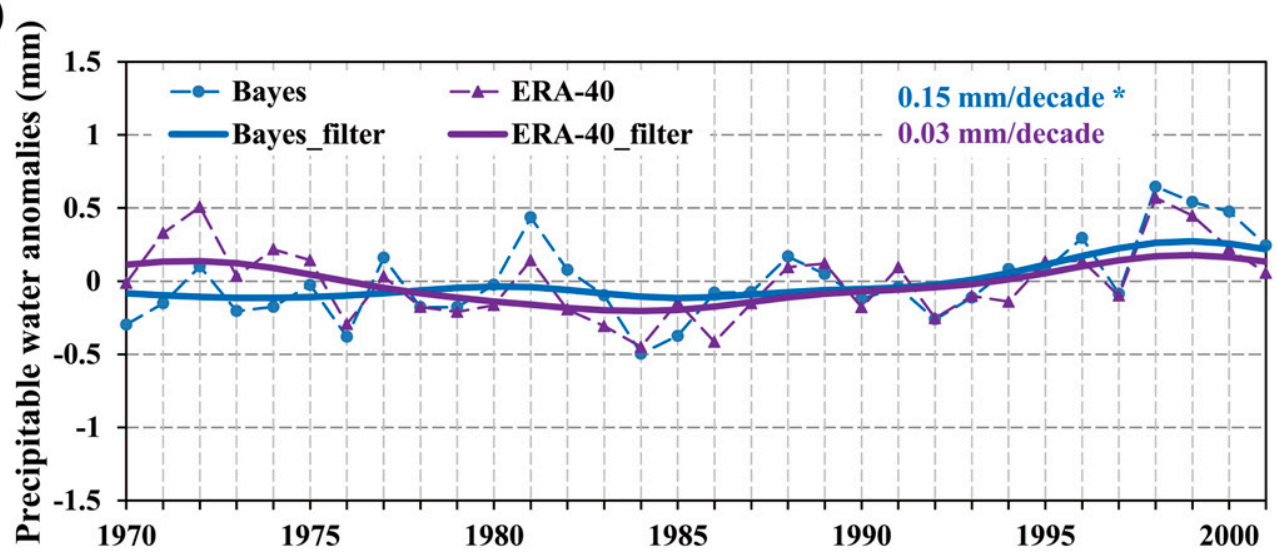

b)

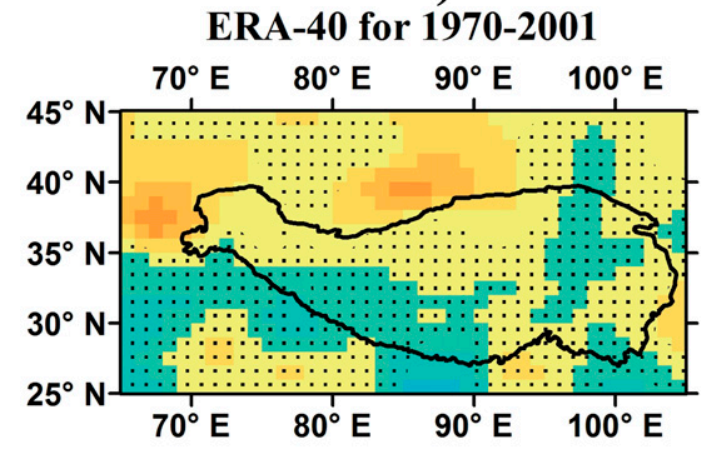

c)

Bayesian estimation for 1970-2001

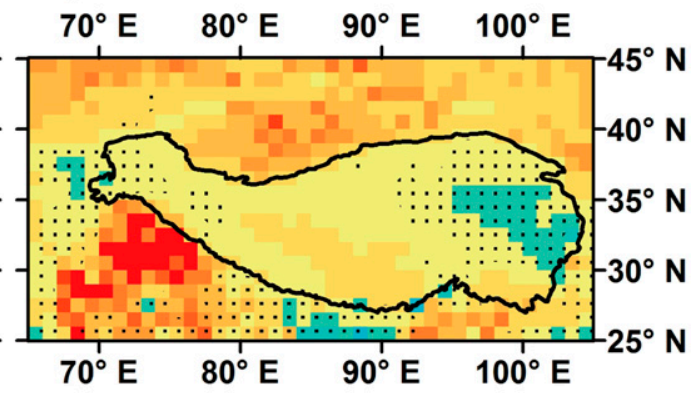

Linear trends 1970-2001 in $\mathrm{mm}$ per decade

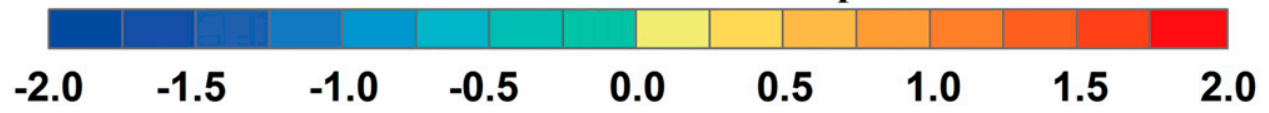

FIG. 7. As in Fig. 6, but for the precipitable water from ERA-40 and Bayesian estimation for 1970-2001.

Bayesian estimation (Fig. 6c), the spatial distribution of linear trends for the JRA-55 (Fig. 6b) shows PW decreases along the southwest side of the Himalayas (mainly over the northeastern Indian subcontinent) and over the northwest part of TP and increases for the rest of the TP, but these increasing trends over the southeast $\mathrm{TP}$ are almost insignificant.

Figure 7 shows the PW trends from Bayesian estimation and ERA-40 for 1970-2001, respectively. The increasing trend of TP PW for $1970-2001$ is $0.15 \mathrm{~mm} \mathrm{decade}^{-1}$ (significant) for the Bayesian estimation and $0.03 \mathrm{~mm} \mathrm{decade}^{-1}$ (insignificant) for ERA-40 (Fig. 7a). It is worth noting that PW variability of ERA-40 after 1987 matches well with that of the Bayesian estimation. This is probably due to the assimilation of moisture data from Special Sensor Microwave Imager from 1987 onward in ERA-40 (Uppala et al. 2005). The agreement between these two independent data suggests that $\mathrm{PW}_{\text {bayes }}$ reveal credible TP PW variability after 1987. Linear trends for ERA-40 (Fig. 7b) show PW decreases over the southwestern and eastern parts of TP and increases for the rest part of TP, but these trends are almost insignificant. While linear trends for the Bayesian estimation (Fig. 7c) show significant PW increases over most of the TP and insignificant decreases over part of the east.

Figure 8 shows the PW trends from Bayesian estimation and ERA-Interim for 1979-2011. The two data series both show significant increasing trend of TP PW for 1979-2011 (Fig. 8a), with 0.21 and $0.12 \mathrm{~mm} \mathrm{decade}^{-1}$, respectively. The curve of PW anomalies of ERAInterim is above the Bayesian estimation before the mid-1990s and below the Bayesian estimation after 1996, resulting in the smaller PW decadal trend. Linear trends for ERA-Interim (Fig. 8b) show PW increases over most of the TP and decreases over the west TP, but the decreasing trends are insignificant. However, linear trends for the Bayesian estimation (Fig. 8c) show PW trends increase over almost all of the TP.

Figure 9 shows the PW trends from Bayesian estimation and MERRA for 1979-2011. The significant increasing 
a)

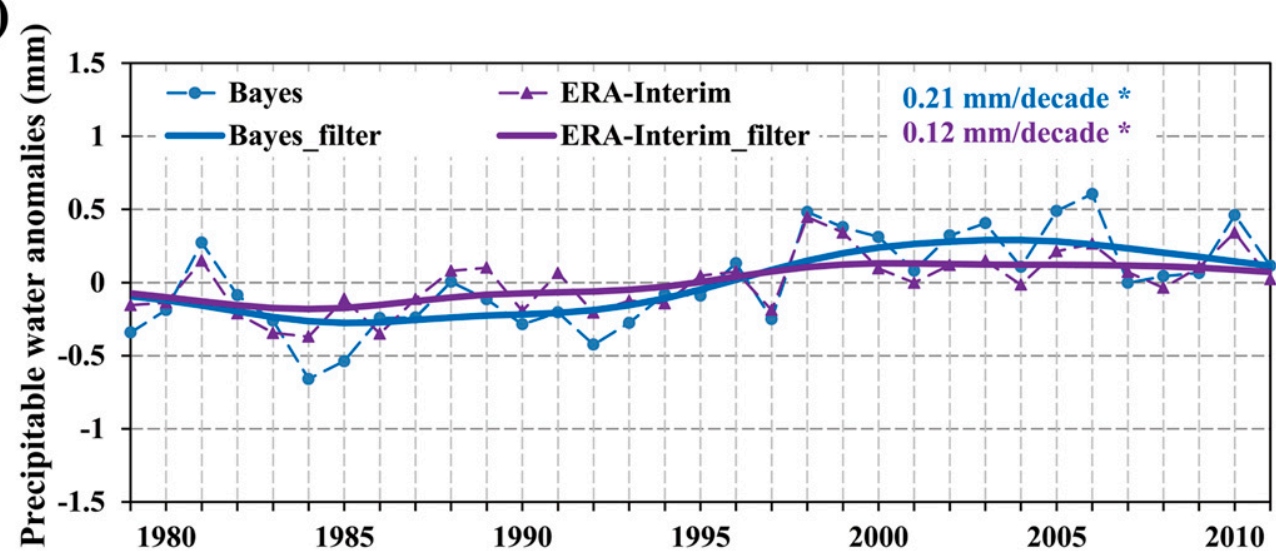

b)

c)

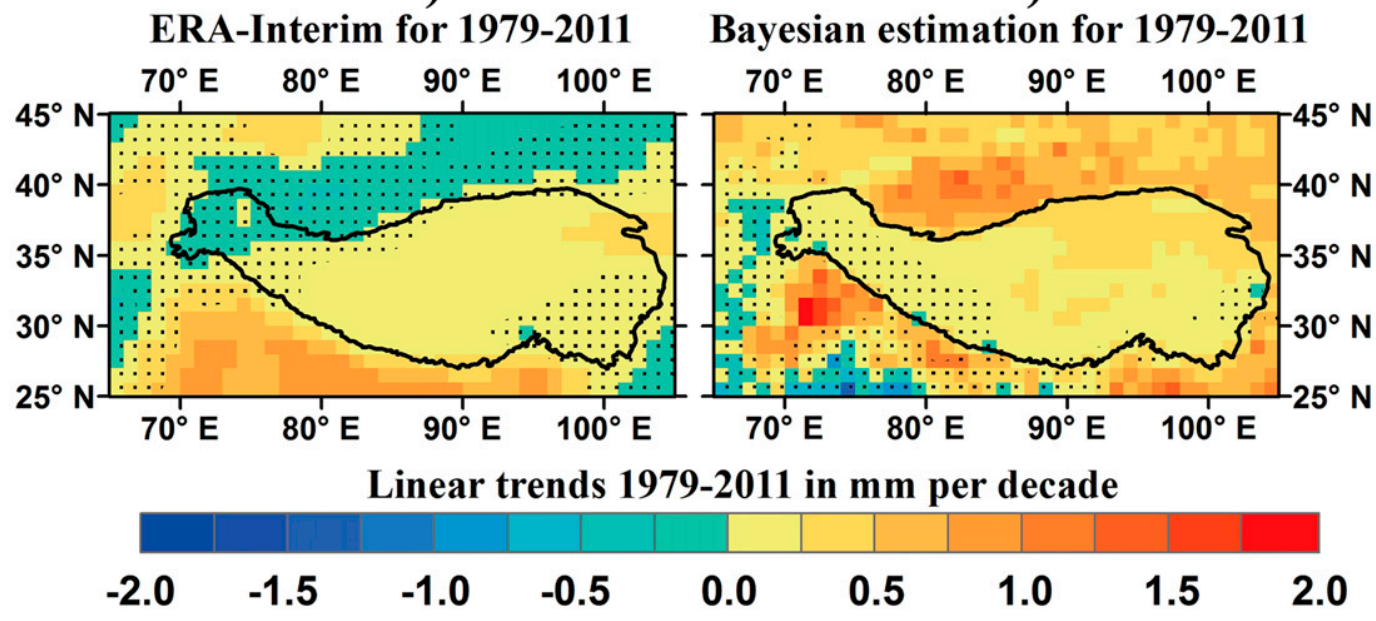

FIG. 8. As in Fig. 6, but for the precipitable water from ERA-Interim and Bayesian estimation for 1979-2011.

trend of TP PW for the MERRA $\left(0.12 \mathrm{~mm} \mathrm{decade}^{-1}\right)$ is the same as ERA-Interim, and the two PW datasets show very similar temporal variations (Figs. 8a and 9a). However, the spatial pattern of linear trends for the MERRA is different from ERA-Interim (Figs. 8b and 9b). The distribution of linear trends for the MERRA (Fig. 9b) shows PW increases over most part of TP and decreases over the western TP and its outer area, with a band of insignificant trends starts from the northwestern TP to the southeastern TP. While linear trends for the Bayesian estimation (Fig. 9c) show PW trends increase over almost all of the TP.

Figure 10 shows the PW trends from Bayesian estimation and NCEP-2 for 1979-2011. The increasing trend of TP PW for 1979-2011 is $0.21 \mathrm{~mm} \mathrm{decade}^{-1}$ (significant) for the Bayesian estimation and $0.06 \mathrm{~mm} \mathrm{decade}^{-1}$ (insignificant) for NCEP-2 (Fig. 10a). The shape of PW anomalies of NCEP-2 show the similar variations as ERA-Interim, but the differences between the Bayesian estimation and NCEP-2 are of larger magnitude. The decrease in PW trends for NCEP-2 (Fig. 10b) appears over not only the eastern part but also the western part. The significant increasing regions of NCEP-2 PW are much smaller as compared with ERA-Interim (Fig. 8b), MERRA (Fig. 9b), or the Bayesian estimation (Fig. 10c).

Figure 11 shows the PW trends from Bayesian estimation and ISCCP for 1984-2006. PW over the TP shows significant increase during these 23 years. The PW trend of the Bayesian estimation is $0.44 \mathrm{~mm} \mathrm{decade}^{-1}$, while the ISCCP is $1.66 \mathrm{~mm} \mathrm{decade}^{-1}$, far beyond the Bayesian estimation. Furthermore, the magnitude of the PW variability of the ISCCP is more than 3 times as much as the Bayesian estimation. Linear trends for the ISCCP (Fig. 11b) also show very a large increase over all of the TP as compared with the Bayesian estimation (Fig. 11c), and much of the increasing trends are insignificant. These big discrepancies in the PW trend and variation imply that the uncertainty in ISCCP PW data may hinder their applications for the TP area. 
a)

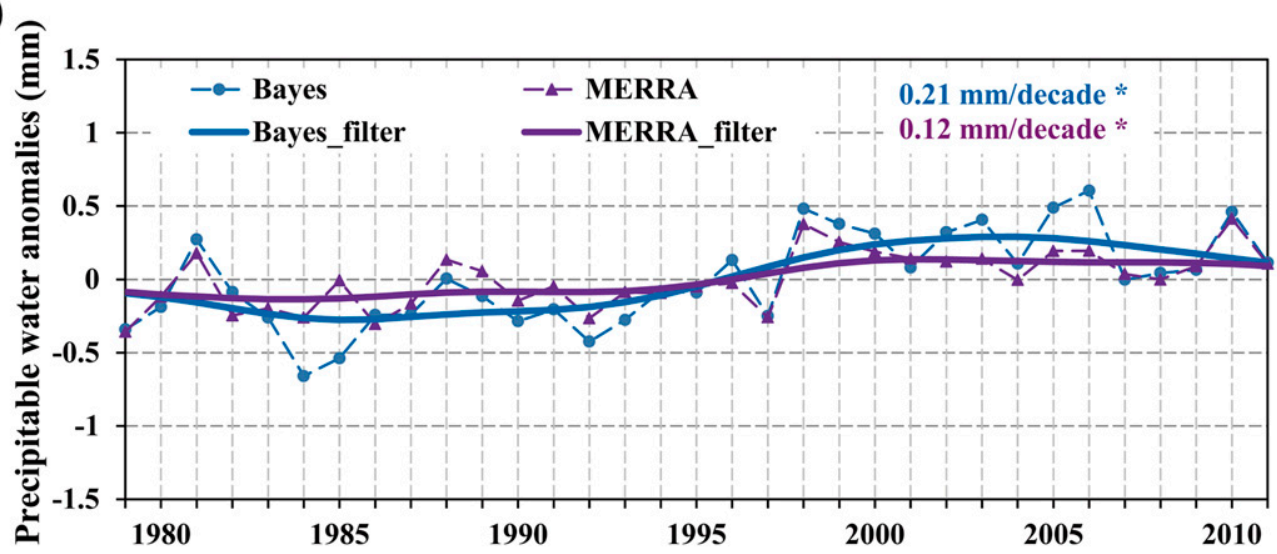

b)
MERRA for 1979-2011

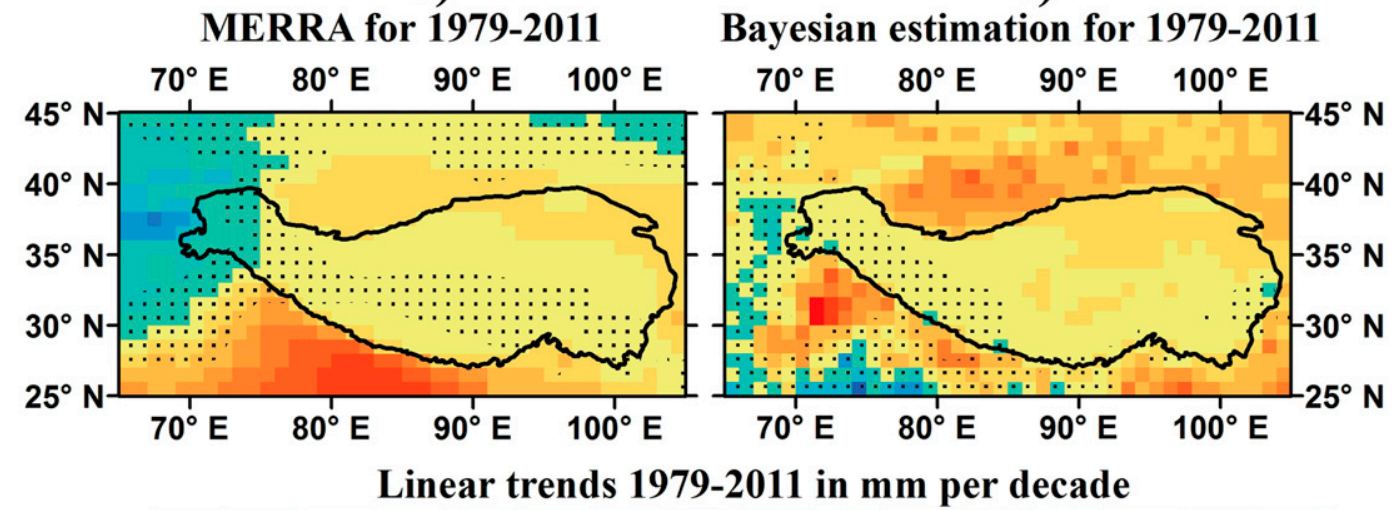

c)

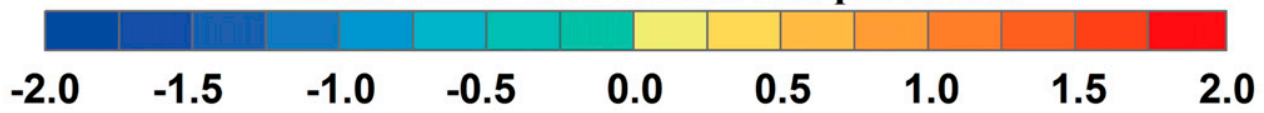

FIG. 9. As in Fig. 6, but for the precipitable water from MERRA and Bayesian estimation for 1979-2011.

\section{Summary}

To detect the long-term trend in PW over the TP, this study proposes a method that uses Bayesian inference theory to reproduce the long-term (1970-2011) and spatially continuous PW from the station temperaturehumidity observations and MODIS PW observations. In this method, the PW spatial distribution of MODIS observations is taken into account as evidence to assign the conditional probability for the PW estimated from station temperature-humidity observations. This probability distribution is formalized as marginal likelihood function in which the weights for each station at each grid point are solved using the expectation maximization iteration to train a Bayesian estimation model. After the Bayesian estimation model is built, long-term PW over the TP at each grid point can be reproduced by importing station PW estimations. Therefore, the advantage of this method is to make use of the strengths of each data source.
As compared with the OLS method, the Bayesian method addresses the overfitting issue by maintaining a balance between model accuracy and complexity and provides a natural way to quantify the uncertainty associated with the model parameters. When the model parameters in the Bayesian method are iteratively estimated, the global maximum may not be found because of the multiple local maxima of log-likelihood function. To address this issue, we define a number of random starting values to optimize the model parameters by choosing the model with the largest log-likelihood value.

In this study, the Bayesian estimation model is built by using monthly-mean PW data from the stations and MODIS for 2000-06 (7 yr) at first. This model is then operated to reproduce the monthly-mean PW for 19702011 over the TP, driven by the station PW estimations for the same period. The performance of the model estimation is evaluated by comparing with the MODIS PW observations grid by grid for 2007-11 and with measured PW at three GPS stations for 1995-2011. 
a)

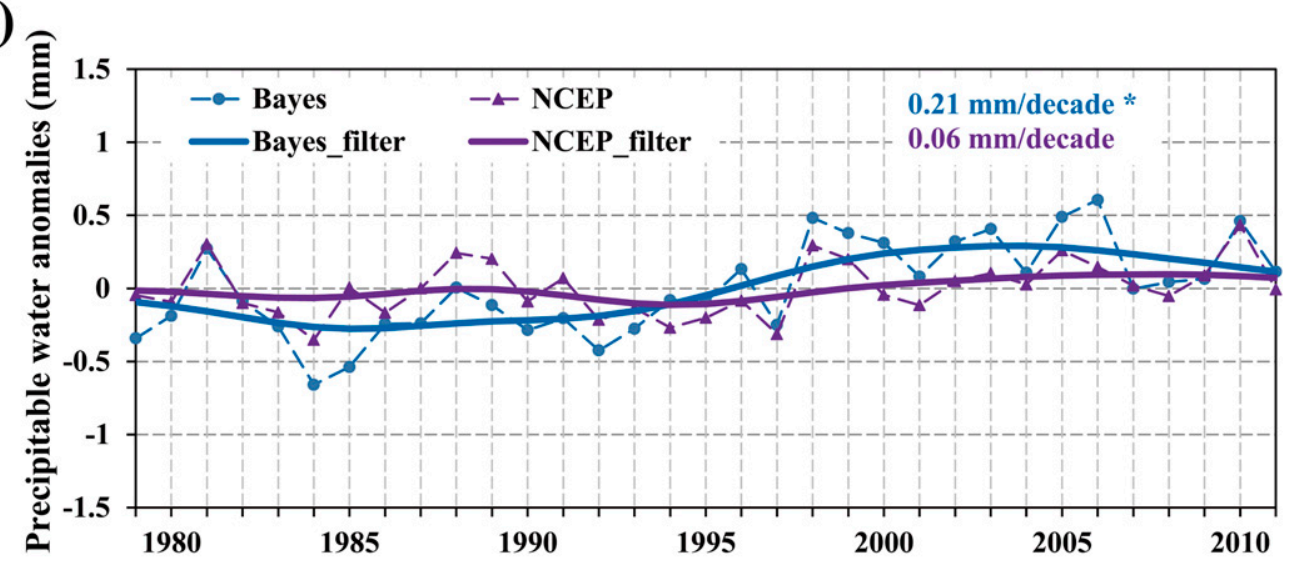

b)

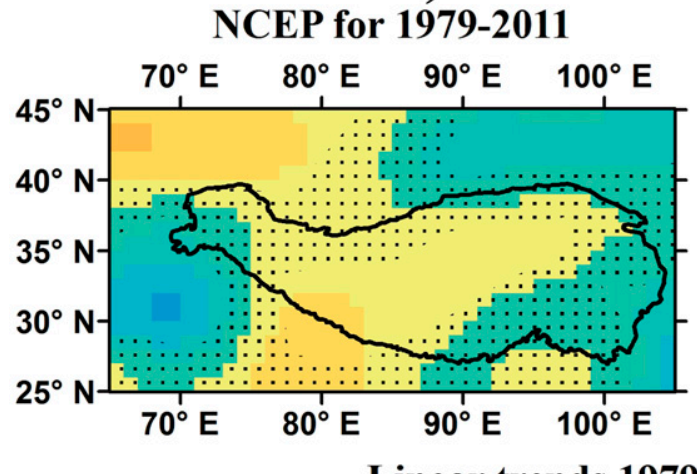

c)

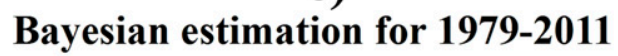

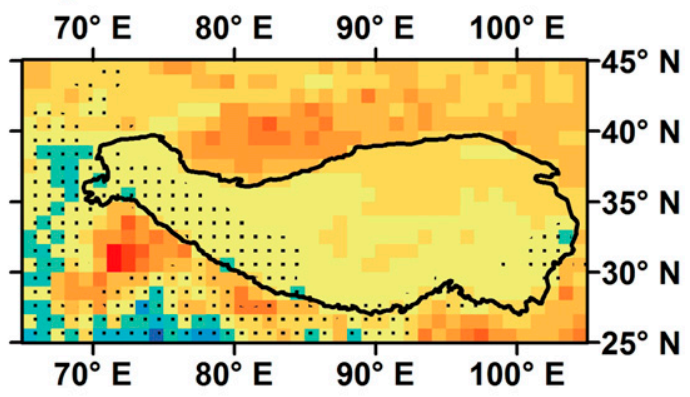

Linear trends 1979-2011 in $\mathrm{mm}$ per decade

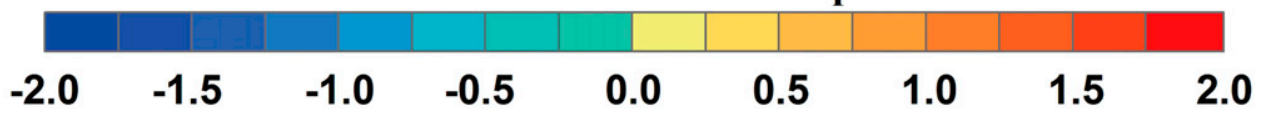

FIG. 10. As in Fig. 6, but for the precipitable water from NCEP-2 and Bayesian estimation for 1979-2011.

The monthly PW anomalies estimated by the Bayesian estimation model agree well with the monthly MODIS PW anomalies, with a correlation coefficient $R$ above 0.80 and an RMSE below $0.65 \mathrm{~mm}$ for each year. The comparison for the TP shows that all the data pairs are quite close to the identity line, with a correlation coefficient $R$ of 0.89 and an RMSE of $0.24 \mathrm{~mm}$. The comparison of annual PW anomalies between the Bayesian estimation and GPS also shows that the agreement is quite good, especially for the LHAZ station on the TP, with a correlation coefficient of 0.85 and an RMSE of $0.32 \mathrm{~mm}$.

As compared with two commonly used interpolation methods (natural neighbor interpolation and inverse distance weighting), the Bayesian estimation model reproduces a $\mathrm{PW}$ spatial pattern over the TP that is very similar to the MODIS PW. Furthermore, for the TP neighboring regions where no station observations are involved, the Bayesian estimation model also has good estimation capability, implying that the atmospheric water vapor over this domain is spatially correlated and this correlation can be captured by the Bayesian estimation model.

The annual PW series for the TP for 1970-2011 derived from the Bayesian model estimation show a significant increasing trend of $0.19 \mathrm{~mm} \mathrm{decade}^{-1}$. The trends in $\mathrm{PW}$ for different subperiods are also detected. During the 42 years, a significant increase of $0.47 \mathrm{~mm}^{\text {decade }}{ }^{-1}$ occurs for 198699 and an insignificant decrease of $-0.09 \mathrm{~mm} \mathrm{decade}^{-1}$ occurs for 2000-11 as well.

From the comparison of the PW data from JRA-55, ERA-40, ERA-Interim, MERRA, NCEP-2, and ISCCP, we find that PW from JRA-55, ERA-40, ERA-Interim, and MERRA have better performances than NCEP-2 and ISCCP. PW variability of ERA-40 is close to the Bayesian estimation after 1987, but the inconsistence of PW variability before 1987 leads to the insignificant trend for ERA-40. ERA-Interim indeed shows the significant increasing trend in PW but less PW variability than the Bayesian estimation. It is interesting to notice that MERRA and ERA-Interim show very similar 
a)

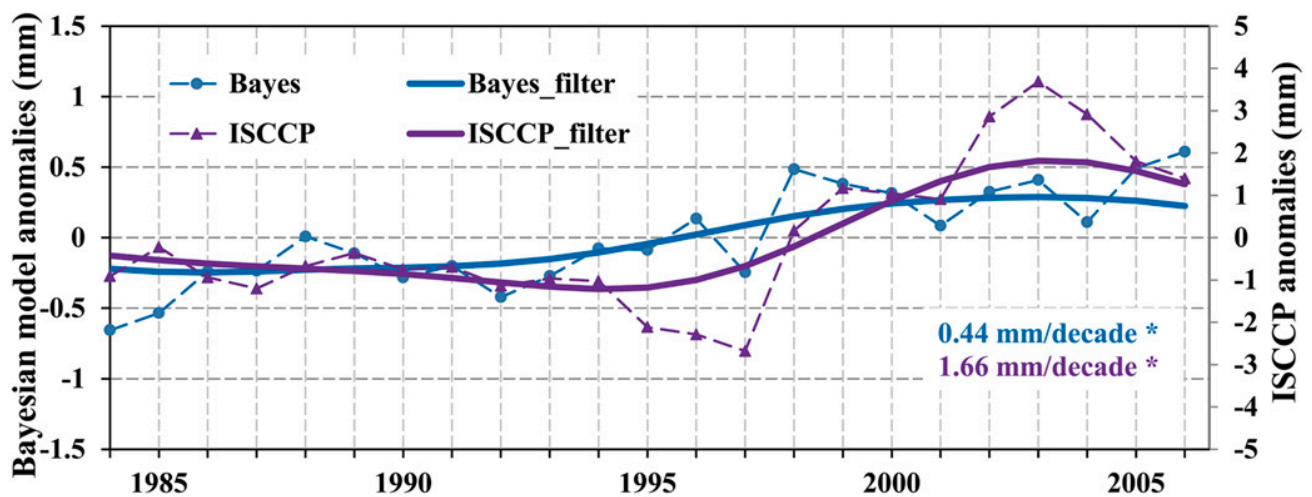

b) ISCCP for 1984-2006 c)
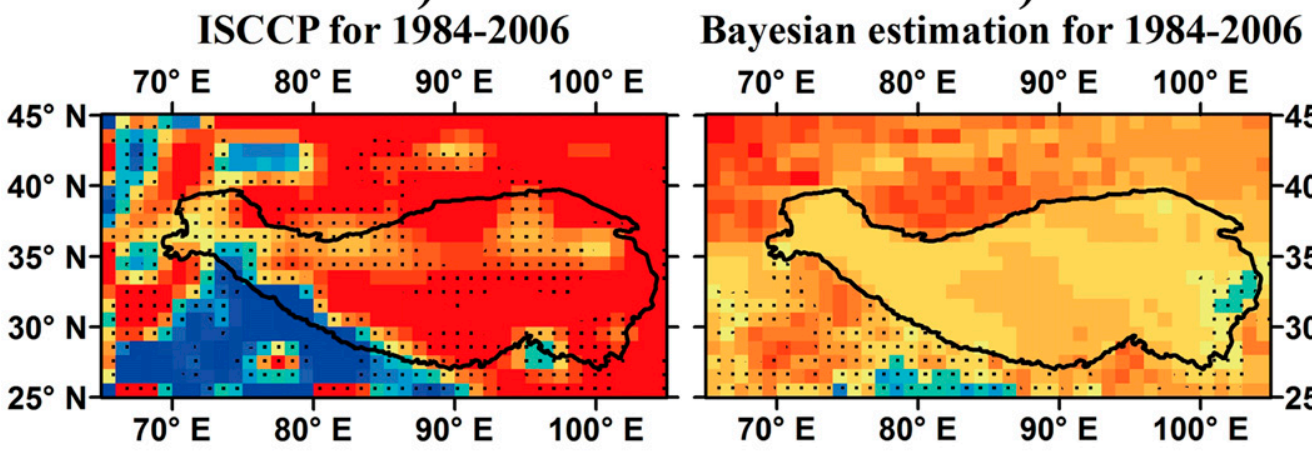

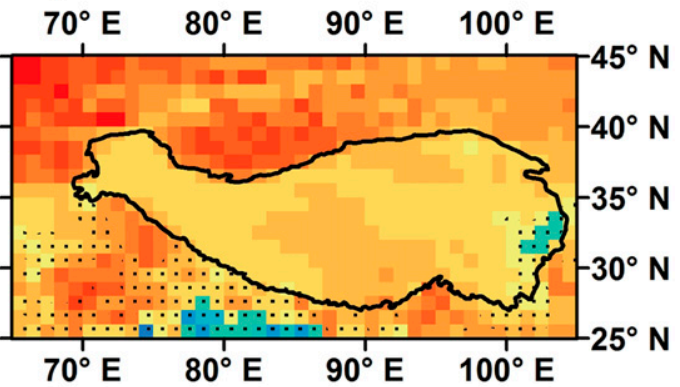

Linear trends 1984-2006 in $\mathrm{mm}$ per decade

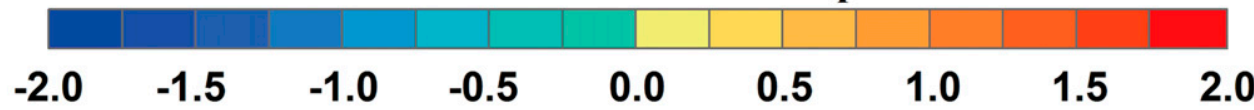

FIG. 11. As in Fig. 6, but for the precipitable water from ISCCP and Bayesian estimation for 1984-2006.

changes in PW over the TP during 1979-2011, while JRA-55 and ERA-40 show very similar changes in PW over the TP before the 1990s. Overall, none of them is able to show the actual trends and variability in PW for the TP like the Bayesian estimation. Furthermore, the PW variations of ERA-40 that are well matched with the Bayesian estimation after 1987 provide independent evidence that verifies the validity of the Bayesian estimation. Readers can directly contact the authors for the long-term PW data to replicate the analyses.

From the evolution of PW series, we notice that the strong PW variability over the TP may have some association with ENSO events. The long-term PW data produced by this study will help to further explore the spatiotemporal relation between these occurrences in the future. Even though this paper focuses on the trend detection and construction of long-term PW for the TP, the method proposed here can be adapted to other climate parameters that are continuously distributed, such as air temperature.
Acknowledgments. This work was supported by the National Natural Science Foundation of China (41371016 and 41001215) and the CAS Youth Innovation Promotion Association. The MODIS water vapor data were obtained from the Goddard Earth Sciences Distributed Active Archive Center (DAAC). The surface relative humidity and air temperature data were obtained from the China Meteorological Administration.

\section{REFERENCES}

Bishop, C. M., 2006: Mixture models and EM. Pattern Recognition and Machine Learning, Springer-Verlag, 423-455.

Chen, T., and E. Martin, 2009: Bayesian linear regression and variable selection for spectroscopic calibration. Anal. Chim. Acta, 631, 13-21, doi:10.1016/j.aca.2008.10.014.

Dee, D. P., E. Källén, A. J. Simmons, and L. Haimberger, 2011: Comments on "Reanalyses suitable for characterizing long-term trends." Bull. Amer. Meteor. Soc., 92, 65-70, doi:10.1175/2010BAMS3070.1.

Dessler, A. E., Z. Zhang, and P. Yang, 2008: Water-vapor climate feedback inferred from climate fluctuations, 2003-2008. Geophys. Res. Lett., 35, L20704, doi:10.1029/2008GL035333. 
Filiberti, M. A., L. Eymard, and B. Urban, 1994: Assimilation of satellite precipitable water in a meteorological forecast model. Mon. Wea. Rev., 122, 486-506, doi:10.1175/1520-0493(1994)122<0486: AOSPWI $>2.0 . \mathrm{CO} ; 2$.

Gao, B.-C., and Y. J. Kaufman, 2003: Water vapor retrievals using Moderate Resolution Imaging Spectroradiometer (MODIS) near-infrared channels. J. Geophys. Res., 108, 4389, doi:10.1029/ 2002JD003023.

- , P. Yang, G. Guo, S. K. Park, W. J. Wiscombe, and B. Chen, 2003: Measurements of water vapor and high clouds over the Tibetan Plateau with the Terra MODIS instrument. IEEE Trans. Geosci. Remote Sens., 41, 895-900, doi:10.1109/ TGRS.2003.810704.

Gao, S., F. Ping, and X. Li, 2006: Tropical heat/water vapor quasiequilibrium and cycle as simulated in a $2 \mathrm{D}$ cloud-resolving model. Atmos. Res., 79, 15-29, doi:10.1016/j.atmosres.2005.04.002.

Gregory, P., 2005: Linear model fitting (Gaussian errors). Bayesian Logical Data Analysis for the Physical Sciences, Cambridge University Press, 243-284.

Kuo, Y.-H., Y.-R. Guo, and E. R. Westwater, 1993: Assimilation of precipitable water measurements into a mesoscale numerical model. Mon. Wea. Rev., 121, 1215-1238, doi:10.1175/ 1520-0493(1993)121<1215:AOPWMI>2.0.CO;2.

Lu, N., J. Qin, K. Yang, Y. Gao, X. Xu, and T. Koike, 2011: On the use of GPS measurements for Moderate Resolution Imaging Spectrometer precipitable water vapor evaluation over southern Tibet. J. Geophys. Res., 116, D23117, doi:10.1029/ 2011JD016160.

- — , Y. Gao, K. Yang, K. E. Trenberth, M. Gehne, and Y. Zhu, 2015: Trends and variability in atmospheric precipitable water over the Tibetan Plateau for 2000-2010. Int. J. Climatol., doi:10.1002/joc.4064, in press.

Neelin, J. D., O. Peters, J. W. Lin, K. Hales, and C. E. Holloway, 2008: Rethinking convective quasi-equilibrium: Observational constraints for stochastic convective schemes in climate models. Philos Trans. Roy. Soc., 366A, 2579-2602, doi:10.1098/ rsta.2008.0056.

Qin, J., K. Yang, N. Lu, Y. Chen, L. Zhao, and M. Han, 2013: Spatial upscaling of in-situ soil moisture measurements based on MODIS-derived apparent thermal inertia. Remote Sens. Environ., 138, 1-9, doi:10.1016/j.rse.2013.07.003.

Reitan, C. H., 1963: Surface dew point and water vapor aloft. J. Appl. Meteor., 2, 776-779, doi:10.1175/1520-0450(1963)002<0776: SDPAWV $>2.0 . \mathrm{CO} ; 2$.

Seko, H., T. Miyoshi, Y. Shoji, and K. Saito, 2011: Data assimilation experiments of precipitable water vapour using the LETKF system: Intense rainfall event over Japan 28 July 2008. Tellus, 63A, 402-414, doi:10.1111/j.1600-0870.2010.00508.x.

Simmons, A. J., K. M. Willett, P. D. Jones, P. W. Thorne, and D. P. Dee, 2010: Low-frequency variations in surface atmospheric humidity, temperature, and precipitation: Inferences from reanalyses and monthly gridded observational data sets. J. Geophys. Res., 115, D01110, doi:10.1029/2009JD012442.
Smith, W. L., 1966: Note on the relation between total precipitable water and surface dew point. J. Appl. Meteor., 5, 726727, doi:10.1175/1520-0450(1966)005<0726:NOTRBT>2.0.CO;2.

Solomon, S., K. H. Rosenlof, R. W. Portmann, J. S. Daniel, S. M. Davis, T. J. Sanford, and G. K. Plattner, 2010: Contributions of stratospheric water vapor to decadal changes in the rate of global warming. Science, 327, 1219-1223, doi:10.1126/science.1182488.

Starr, D. O., and S. H. Melfi, 1990: The role of water vapor in climate: A strategic research plan for the proposed GEWEX water vapor project (GVap). NASA Rep. NAS 1.55:3120, 50 pp.

Thorne, P. W., and R. S. Vose, 2010: Reanalyses suitable for characterizing long-term trends. Bull. Amer. Meteor. Soc., 91, 353-361, doi:10.1175/2009BAMS2858.1.

Trenberth, K. E., J. T. Fasullo, and J. Kiehl, 2009: Earth's global energy budget. Bull. Amer. Meteor. Soc., 90,311-324, doi:10.1175/ 2008BAMS2634.1.

$\longrightarrow,-\longrightarrow$, and J. Mackaro, 2011: Atmospheric moisture transports from ocean to land and global energy flows in reanalyses. J. Climate, 24, 4907-4924, doi:10.1175/2011JCLI4171.1.

Uppala, S. M., and Coauthors, 2005: The ERA-40 Re-Analysis. Quart. J. Roy. Meteor. Soc., 131, 2961-3012, doi:10.1256/qj.04.176.

Wang, J., L. Zhang, A. Dai, T. Van Hove, and J. Van Baelen, 2007: A near-global, 8-year, 2-hourly atmospheric precipitable water dataset from ground-based GPS measurements. J. Geophys. Res., 112, D11107, doi:10.1029/2006JD007529.

Xu, X., X. Shi, Y. Wang, S. Peng, and X. Shi, 2008: Data analysis and numerical simulation of moisture source and transport associated with summer precipitation in the Yangtze River valley over China. Meteor. Atmos. Phys., 100, 217-231, doi:10.1007/ s00703-008-0305-8.

Yang, K., T. Koike, H. Fujii, T. Tamura, X. Xu, L. Bian, and M. Zhou, 2004: The daytime evolution of the atmospheric boundary layer and convection over the Tibetan Plateau: Observations and simulations. J. Meteor. Soc. Japan, 82, 17771792, doi:10.2151/jmsj.82.1777.

,-- , P. Stackhouse, C. Mikovitz, and S. J. Cox, 2006: An assessment of satellite surface radiation products for highlands with Tibet instrumental data. Geophys. Res. Lett., 33, L22403, doi:10.1029/2006GL027640.

_ , B. Ding, J. Qin, W. Tang, N. Lu, and C. Lin, 2012: Can aerosol loading explain the solar dimming over the Tibetan Plateau? Geophys. Res. Lett., 39, L20710, doi:10.1029/2012GL053733.

Zhai, P., and R. E. Eskridge, 1997: Atmospheric water vapor over China. J. Climate, 10, 2643-2652, doi:10.1175/1520-0442(1997)010<2643: AWVOC $>2.0 . \mathrm{CO} ; 2$.

Zhang, D., J. Huang, X. Guan, B. Chen, and L. Zhang, 2013: Longterm trends of precipitable water and precipitation over the Tibetan Plateau derived from satellite and surface measurements. J. Quant. Spectrosc. Radiat. Transfer, 122, 64-71, doi:10.1016/ j.jqsrt.2012.11.028.

Zhou, T. J., and R. C. Yu, 2005: Atmospheric water vapor transport associated with typical anomalous summer rainfall patterns in China. J. Geophys. Res., 110, D08104, doi:10.1029/2004JD005413. 